\section{O processo de} tombamento da primeira sede do Museu Nacional

\section{na atual Praça da República - Rio de Janeiro}

\section{Ana Lúcia de Abreu Gomes [*]}

Maria Margaret Lopes[**]

[*] Universidade de Brasília (UnB), Brasília,

DF, Brasil. anaabreu.68@gmail.com

ORCID: https://orcid.org/0000-002-4478-333X

[**] Universidade de São Paulo (USP), Museu de Arqueologia e Etnologia (MAE), São Paulo, SP, Brasil. mmargaretlopes@gmail.com ORCID: https://orcid.org/0000-0002-9803-8378
Resumo: O objetivo deste artigo é discutir os usos do passado por meio da análise do processo de tombamento federal de prédio situado à Praça da República, 26, na cidade do Rio de Janeiro. O edifício abrigou diferentes instituições ao longo de seus quase 200 anos de existência. Entretanto, por meio da análise dos pareceres técnico e jurídico que instruíram o processo de tombamento, observa-se a construção de passados para o edifício, como o de ter sediado o Arquivo Nacional e, especialmente, ter sido a primeira sede do Museu Nacional. Outro passado construído para o edifício é o de sua participação na própria construção daquele lugar, o antigo Campo de Santana.

Palavras-chave: Museu Nacional; Tombamento; Museologia.

Abstract: The purpose of this paper is discuss the uses of the past by analyzing the classification process of a building located at 26, Praça da República, in the city of Rio de Janeiro. The building housed different institutions throughout its almost 200 years of existence. However, through the analysis of the technical and legal opinions that guided the classification process, one observes the construction of past to the building, as the one to have hosted the National Archive and, especially, to have been the first headquarters of the National Museum. Another past built for the building is that of its participation in the very construction of that place, the old Campo de Santana.

Keywords: National Museum; Classification; Museology. 


\section{Introdução}

$\mathrm{N}$ o dia 2 de setembro de 2018, o Museu Nacional, a mais longeva instituição museal do país até então, foi consumido por um incêndio. Meses antes, mais precisamente em 6 de junho, completara 200 anos (1818-2018). A instituição custodiava, desde 1892, ou seja, durante 126 anos, a maior coleção de história natural da América Latina, ocupando todo o Palácio da Quinta da Boa Vista, em São Cristóvão, bairro da Zona Norte do Rio de Janeiro.

A sede do Museu Nacional na Quinta da Boa Vista foi um dos imóveis tombados pelo então Serviço do Patrimônio Histórico e Artístico Nacional (Sphan) ao longo de seu primeiro ano de atuação, mais precisamente em 30 de junho de $1938 .{ }^{1}$

A certidão de tombamento existente no processo nos informa que o Palácio da Quinta da Boa Vista foi inscrito no Livro de Tombo Histórico (inscrição n. 68, fls.13) e no Livro de Tombo de Belas Artes (inscrição n. 154, fls. 27).

Destaca-se que os critérios históricos apresentados na certidão de tombamento envolviam o papel daquela construção/palácio na História do Brasil, como sede da residência da Família Real e Imperial; ${ }^{2}$ já os critérios estéticos diziam respeito às características arquitetônicas e artísticas neoclássicas que viabilizaram sua inscrição no Livro do Tombo de Belas Artes.

A inscrição do Palácio da Quinta da Boa Vista tanto no Livro de Tombo de Belas Artes quanto no Livro de Tombo Histórico se deu ex-officio, uma vez que se tratava de prédio da União, conforme orienta o artigo 5o do Decreto-Lei 25/1937. ${ }^{3}$ Pelo uso desse dispositivo legal, não houve propriamente a instrução de um processo que pudesse nos revelar, hoje, os critérios mais específicos (além daqueles destacados na certidão) identificados à época como justificativa para seu tombamento.

Ao nos voltarmos para aquele ano de 1938, destacamos três aspectos que nos fazem inferir o porquê da decisão pelo tombamento do Palácio: primeiro, a recorrência a um dispositivo discursivo que Gonçalves (1996) identificou como "a retórica da perda”, por meio do qual se ressaltava a urgência em salvar um patrimônio sempre ameaçado, sempre necessitado de defesa; em segundo lugar, essa urgência, dita e reiterada várias vezes, por salvar um bem móvel ou imóvel em vias de extinção, caso não se tomassem providências urgentes, se

1 Processo 099-T-38. O tombamento foi do edifício. A única coleção do Museu Nacional tombada naquele contexto foi a Coleção Arqueológica Balbino de Freitas. O processo de tombamento é o de número 77-T-1938. A Coleção está inscrita sob o n. 14, no Livro de Tombo Arqueológico, Etnográfico e Paisagístico, e data de 14 de abril de 1938

2 Para uma descrição do antigo uso do edifício como moradia da família real, ver Dantas, 2007.

3 Por esse artigo, é facultado ao diretor do Serviço do Patrimônio Histórico e Artístico Nacional o tombamento de ofício de bens móveis e imóveis da União, estados e municípios. 
agudizava pela falta de funcionários nesse serviço. Em entrevista concedida por Rodrigo Melo Franco de Andrade em 29 de junho de 1958, ele sinalizava que sua equipe era de menos de 20 funcionários (Andrade, 1987, p. 40). Por fim, devemos mencionar a correspondência da então vice-diretora do Museu Nacional, Heloísa Alberto Torres, para o então diretor do Sphan, Rodrigo Melo Franco de Andrade, datada de 9 de maio de 1936, ${ }^{4}$ sugerindo a proteção do prédio: "A organização desses trabalhos de defesa não pode ser iniciada pela mutilação de um instituto centenário e glorioso quando um dos primeiros monumentos nacionais a serem tombados pelo Serviço projetado deveria ser certamente o Museu Nacional" (Andrade, 1987, p. 150).

Tal tombamento, entretanto, junto a outros mecanismos de proteção, não impediu que um incêndio de grandes proporções destruísse praticamente todo o acervo e comprometesse sua estrutura física.

Este artigo, entretanto, tem por objetivo analisar o processo de tombamento do edifício que foi a primeira sede do Museu Nacional, situado também no Rio de Janeiro, mas na Praça da República, mais precisamente no número 26 dessa praça.

Tal processo foi aberto a partir de solicitação da Presidência da Casa da Moeda, datada de 12 de agosto de 2009 e encaminhada à Presidência do Instituto do Patrimônio Histórico e Artístico Nacional (Iphan). Um dos argumentos destacados para o pedido de tombamento nessa solicitação foi justamente o fato de o edifício ter sido a primeira sede do Museu Nacional entre os anos de 1818 e 1892 . O proponente do pedido destaca que, além de ter abrigado o Museu Nacional, o prédio foi sede do Arquivo Nacional. Não foram ressaltadas as características arquitetônicas do prédio, mesmo porque a Presidência da Casa da Moeda esclarecia que o prédio em tela seria objeto de restauração e adaptação.

Chamaram nossa atenção a justificativa do pedido de 2009 e os critérios apresentados para a inscrição no Livro de Tombo Histórico do Palácio da Quinta da Boa Vista em 1938. Se uma determinada dimensão histórica do tempo nos permite perceber diferenças entre o passado e o presente, pareceu-nos que os argumentos apresentados em ambos os casos, mesmo com lapso temporal de 70 anos entre eles, eram bastante próximos.

Portanto, identificamos nesse processo, aberto em decorrência do pedido de tombamento feito pela Casa da Moeda, elementos que podem nos ajudar a pensar de que forma a política de patrimônio contribuiu e contribui para a atribuição de valores, para o agenciamento

${ }^{4}$ Em que pese a criação do Serviço de Patrimônio Histórico e Artístico Nacional ter ocorrido por meio da Lei 378, de 13 de janeiro de 1937, que reorganizou o então Ministério da Educação e Saúde Pública, a historiografia sobre a criação do Serviço do Patrimônio Histórico e Artístico Nacional (Sphan) sinaliza que o presidente Getúlio Vargas, mediante solicitação formal do ministro Gustavo Capanema ao presidente da República, autorizou o funcionamento do Serviço de forma provisória desde abril de 1936 (REZENDE et al., 2015). 
de elementos do passado concorrendo igualmente para a construção de "inteligibilidades acerca desse passado" (Cavalcante, 2016, p. 17).

Sendo assim, propomos neste artigo desenvolver uma análise desse processo por meio da documentação apresentada pelo proponente do tombamento, no caso, a própria Presidência da Casa da Moeda (detentora do edifício desde 1986), e dos pareceres e notas técnicas produzidos pelos servidores do Iphan constantes do processo de tombamento em tela.

O processo de Tombamento recebeu o número 1600-T-2010 e é composto de dois volumes e dois anexos. No primeiro volume, de 198 páginas, constam, dentre outros documentos, uma Instrução Técnica (n. 228/2009) e um parecer (005/2010), ambos elaborados por arquitetos do Iphan. Outro parecer, de n. 008/2010, foi elaborado por técnico da área de engenharia e história da arte. O volume 2 apresenta 79 páginas, e dele consta o parecer jurídico do processo. $\mathrm{O}$ anexo 1 é composto de 131 páginas. Dele constam os resultados da pesquisa documental realizada no Arquivo Nacional e os relatórios da arqueóloga Guadalupe Campos (na íntegra) e da historiadora Evelyne Azevedo (em parte). O anexo 2 apresenta apenas duas páginas, sendo uma de abertura do volume e outra da capa do Projeto de Restauração e Adaptação do Museu e Centro Cultural da Casa da Moeda.

Além desses documentos, este artigo tomará por base o parecer do Conselho Consultivo do Patrimônio Cultural (CCPC) e as discussões que esse pedido suscitou e que se encontram registradas em ata do referido Conselho que deliberou pelo tombamento do prédio. $^{5}$

Aqui acreditamos caber uma observação acerca dos aspectos teórico-metodológicos que nortearam o desenvolvimento deste artigo. Primeiramente, cabe destacar que compreendemos a documentação que instrui o processo (cuja discussão é central neste artigo), a ser aqui apresentada e analisada não como um reflexo da realidade ou uma possibilidade de acesso direto ao passado, como tantos historiadores e estudiosos já advertiram. ${ }^{6}$ Não nos é possível revelar o passado tal qual ele ocorreu. Acerca dessa impossibilidade de acessar o passado por meio dos vestígios que nos chegam, Roland Barthes (2004) já sinalizava aos historiadores um paradoxo para o qual eram necessárias bastante atenção e vigilância:

O discurso histórico supõe, se assim se pode dizer, uma dupla operação, bastante arrevesada. Num primeiro momento [...] o referente é destacado do discurso, fica-lhe exterior, fundador, é considerado como seu regulador: é o tempo da res gestae, e o

\footnotetext{
${ }^{5}$ A referida ata encontra-se disponível no portal do Iphan: http://portal.iphan.gov.br/uploads/atas/ATA_80a_Reuniao_do_ Conselho_Consultivo_17_09_2015.pdf.

${ }^{6}$ Sobre o tema há vasta bibliografia. Cito, apenas a título de exemplo: Michel de Certeau, em A escrita da história; Michel Foucault, em Arqueologia do saber; Keith Jenkins, em A história repensada; Jacques Le Goff, em História e memória; E. Carr, em Que é história?; Hayden White, em Trópicos do discurso, dentre outros.
} 
discurso se dá simplesmente como historia rerum gestarum, mas num segundo momento, é o próprio significado que é rechaçado, confundido no referente; o referente entra em relação direta com o significante e o discurso, encarregado, apenas de exprimir o real, acredita fazer a economia do termo fundamental das estruturas imaginárias, que é o significado. Como todo o discurso de pretensão "realista", o da história acredita conhecer apenas um esquema semântico de dois termos, o referente e o significante; a confusão (ilusória) do referente com o significado define, como se sabe, os discursos sui-referenciais, como o discurso performativo; pode-se dizer que o discurso histórico é um discurso performativo com trucagem, em que o constativo (descritivo) aparente não é de fato, mais do que o significante do ato da palavra como ato de autoridade. (Barthes, 2004, p. 177-178)

Como se poderá observar em nosso processo de tombamento, ele foi instruído com um conjunto de vestígios que, ao serem selecionados para compor o processo de tombamento, são elevados à categoria de acontecimentos, de fatos. Eles não são em si acontecimentos ou fatos. Sinalizando que não discordamos absolutamente do tombamento do edifício (ao contrário), buscaremos analisar o próprio processo de tombamento aberto pelo Iphan com o objetivo de dar a conhecer como determinados vestígios foram agenciados e, ao conformá-los no interior de um processo administrativo, são capazes de construir um discurso acerca desse passado.

\section{O processo e o Conselho}

Em 17 de setembro de 2015, em sua 80ª Reunião, o Conselho Consultivo do Patrimônio Cultural (CCPC) aprovou o tombamento do prédio sito à Praça da República, 26, na cidade do Rio de Janeiro, entre as atuais ruas da Constituição e Visconde do Rio Branco. ${ }^{7}$ A inscrição foi feita no Livro de Tombo Histórico do Iphan.

O prédio mencionado pertence à Casa da Moeda do Brasil (CMB) desde 1986 e abriga, hoje, seu Centro Cultural, inaugurado recentemente. ${ }^{8}$ Foi a própria CMB que, em 2009, protocolou o pedido de tombamento do prédio. Instruído, tal pedido foi objeto de

\footnotetext{
A Praça da República recebeu esse nome com a Proclamação da República, em 15 de novembro de 1889. O local até então era conhecido como Campo de Santana e também Campo (ou Praça) da Aclamação, quer por abrigar a igreja cujo orago era a avó de Maria - Ana, daí Campo de Santana, quer por ter sido o local da cerimônia de Aclamação de Pedro I. O prédio, naquela ocasião, situava-se entre a rua do Conde e a rua dos Ciganos, hoje Visconde do Rio Branco e Constituição, respectivamente.

${ }^{8}$ Em 9 de março de 2018.
} 
apreciação na citada 80aㅡ Reunião do CCPC. ${ }^{9}$ O Ofício da Presidência da Casa da Moeda já justificava o pedido, selecionando quatro momentos, considerados emblemáticos da trajetória do prédio: como residência do barão de Ubá, como sede do Museu Nacional, como sede do Arquivo Nacional e como edificação pertencente à Casa da Moeda.

Em um primeiro momento, tanto a Coordenadora do Departamento de Patrimônio Material na cidade do Rio de Janeiro quanto a arquiteta que emitiu nota técnica destacaram a ausência de documentação em que pudessem se basear para proceder à análise do pedido. A arquiteta do Iphan observou que, paralelamente ao pedido de tombamento, havia um projeto de requalificação do edifício para que este passasse a ser sede do Centro Cultural da Casa da Moeda. De forma cautelosa, a arquiteta propôs que se aguardasse o término das obras de requalificação do prédio e a inauguração do Centro Cultural para que o pedido de tombamento fosse avaliado.

A Presidência da Casa da Moeda se antecipou e apresentou, em caráter de aditamento ao pedido original, um dossiê contendo documentação que justificaria o pedido de tombamento. Pois bem: qual a seleção de vestígios do passado feita para justificar o pedido de tombamento?

Primeiramente, o fato de a construção do prédio ter sido ordenada, no início do século XIX, por João Rodrigues Pereira de Almeida (1781-1830) - barão de Ubá, um dos mais ricos comerciantes portugueses na cidade do Rio de Janeiro, que comprara o terreno da Ordem Terceira do Carmo em 1807 (Gonçalves, 2004, p. 255) para construir ali sua residência. Sua riqueza e prestígio advinham de intensa e variada atividade econômica. João Rodrigues Pereira de Almeida era comerciante de grosso trato, traficava escravos, era um dos principais importadores de produtos gaúchos para o Rio de Janeiro e arrematava quintos e dízimos no Rio Grande do Sul, monopolizando, por diversas ocasiões, esses setores (Fragoso, 1998, p. 327-329). Foi nomeado, em diferentes ocasiões, diretor do Banco do Brasil. Por ter laços estreitos com o então imperador Pedro I, recebeu o título de barão de Ubá a 12 de outubro de 1828, como parte das comemorações do aniversário do imperador (Gonçalves, 2004, p. 323).

O edifício em questão foi, posteriormente, comprado pelo governo português, em 6 de junho de 1818, com o objetivo de abrigar o Museu Real. No documento de compra do imóvel e que o institui como museu, afirma-se que seu proprietário, voluntariamente, propunha sua venda pelo valor de 32:000\$000 (trinta e dois contos de réis). ${ }^{10} \mathrm{O}$ Museu Real, posteriormente Imperial e Nacional, ocupou o prédio por 74 anos, de 1818 a 1892.

\footnotetext{
${ }^{9}$ Em 1993, o prefeito da cidade do Rio de Janeiro, César Maia, tombara provisoriamente o prédio em tela. Ver Decreto 11.971, de 17 de março de 1993. O pedido de tombamento teve a iniciativa do Tribunal de Justiça do Estado do Rio de Janeiro, que encaminhara o ofício P/156, de 1992 (Processo 1600-T-2010, p. 118).

10 Decreto de 6 de junho de 1818. Museu Nacional. Doc. Mus. Nac. 2, pasta 1.
} 
O referido imóvel, como tantos outros em nossas cidades, ao ser selecionado e elevado à categoria de monumento, se revela como um palimpsesto. São camadas e mais camadas de "história" que são elaboradas por meio de interpretações que têm como finalidade construir um determinado passado para o edifício que, assim elaborado, legitima o seu tombamento. Da forma como esse discurso é formulado, conforme nos advertiu Barthes (2004), é possível entender que a história pode ser identificada em seu interior, em suas fachadas, em decorrência das alterações ali promovidas. Ou seja, que o real possa existir além do discurso.

A documentação que instrui o processo destaca que, em meados do século XIX, várias intervenções foram executadas em um prédio que fora construído para sediar uma residência e que acabara abrigando um museu. ${ }^{11} \mathrm{O}$ prédio acolheu, concomitantemente ao Museu Nacional, o Instituto Histórico e Geográfico Brasileiro (IHGB), sessões e o museu (Lopes; Figueirôa, 2019) da Sociedade Auxiliadora da Indústria Nacional (Sain), sessões da Sociedade Velloziana, do Imperial Instituto Fluminense de Agricultura, aulas do Ginásio Brasileiro e do Conservatório de Música, entre outras (Lopes, 2009, p. 73-79). Em meio a um conjunto de documentos de arquivo consultados, Lopes identificou uma recorrência: os gestores do museu ao longo do século XIX reclamavam da falta de espaço (Lopes, 2009, p. 163).

Foram justamente essas intervenções feitas no edifício ao longo de todos aqueles anos do Oitocentos, e igualmente no século XX, para adequar o edifício à função de Arquivo Nacional, que o descaracterizaram, considerando os aspectos arquitetônicos e plásticos.

Segundo argumentação constante dos pareceres da área de arquitetura do Iphan, as alterações no edifício tiveram relação com suas diferentes ocupações ao longo de seus mais de 200 anos de uso: primeiramente, Museu Real, de 1818 a 1892, ${ }^{12}$ e, em seguida, Intendência de Guerra e Fórum da Cidade do Rio de Janeiro, até 1906, quando foi desocupado para abrigar o Arquivo Nacional, que nele permaneceu até 1985, momento em que o prédio passou para a Casa da Moeda do Brasil (CMB).

O processo de tombamento destaca que as intervenções feitas no prédio, à época, ${ }^{13}$ para abrigar o Arquivo Nacional, foram as mais significativas, inclusive em sua fachada, que recebeu um pórtico que o transformou em um edifício em estilo "neoclássico tardio". ${ }^{14} \mathrm{O}$ processo destaca que se acrescentou um terceiro andar, além de inúmeras alterações internas, inclusive a introdução de uma escada em ferro e mármore e um elevador, instalado em

\footnotetext{
"Em 21 de agosto de 1855, por exemplo, o jornal Correio Paulistano noticiava que ainda não estavam concluídas as reformas realizadas no edifício, principalmente no teto e no madeiramento (LOPES, 2013).

${ }^{12}$ De 1818 a 1822, denominava-se Museu Real; de 1822 a 1830, Museu Imperial; e de 1830 até o presente momento, Museu Nacional.

13 Segundo o processo de tombamento 1600-T-2010, as reformas são do arquiteto Rafael Rebecchi, a partir de projeto do engenheiro Francisco Augusto Peixoto.

${ }^{14}$ Ver folha 8 do processo 1600-T-2010.
} 
1908. Já na década de 1950 houve a construção de pisos intermediários e de novas colunas desde o primeiro andar, dentre outros (Iphan, Processo de Tombamento 1600-T-2010, p. 135-138).

O Arquivo Nacional ocupou o imóvel por 72 anos, de 1907 a 1985, praticamente o mesmo tempo ocupado anteriormente pelo Museu Nacional, de 1818 a 1982, ou seja, 74 anos. Em 1986, o prédio foi entregue à Casa da Moeda do Brasil (CMB), que o cedeu, em 1988, ao Tribunal do Estado do Rio de Janeiro, para instalação de seu Departamento Geral de Arquivo e Documentação Histórica, que nele permaneceu até 1998. Por fim, segundo informações apresentadas no processo, o prédio retorna à Casa da Moeda, ficando então, sem uso.

Todo o processo de adequação do imóvel ao longo dessa trajetória de quase 200 anos não foi empecilho para que o então prefeito do Rio de Janeiro, Eduardo Paes, expedisse Decreto tombando em definitivo ${ }^{15}$ o referido prédio, com base na decisão do Conselho Municipal de Patrimônio Cultural da Cidade do Rio de Janeiro. O texto do Decreto 30.721, de 19 de maio de 2009, destaca o valor histórico do imóvel, especialmente o fato de ter abrigado "o Museu Real (atual Museu Nacional), a Intendência de Guerra e Fórum da Cidade do Rio de Janeiro, o Arquivo Nacional e o Arquivo Geral do Tribunal de Justiça do Estado do Rio de Janeiro".

Seis anos depois, em 2015, o Conselho Consultivo do Patrimônio Cultural aprovou o tombamento federal do prédio, acompanhando o parecer do arquiteto Conselheiro Nestor Goulart Reis Filho. Nesse parecer, Nestor Goulart observa e acolhe uma série de ponderações de natureza técnica feitas ao longo da instrução do processo.

A primeira análise técnica da Superintendência do Iphan no Rio de Janeiro, realizada pela área de arquitetura em dezembro de 2009, por meio da Informação 228, destaca que as intervenções pelas quais o imóvel passou mantiveram "pouco alteradas as fachadas e a volumetria do prédio principal, elementos esses resultantes da grande reforma havida em 1906-1908" (Processo de tombamento 1600-T-10, v. 1, p. 7). Quanto ao interior do prédio, o parecer n. 05/2010, também da área de arquitetura da Superintendência do Iphan no Rio de Janeiro, indica que a mudança do uso do prédio, de museu para arquivo, implicou uma demanda de suporte de carga que foi um dos motivos para as significativas alterações ocorridas em seu interior (ibidem, p. 127-144). O parecer ressalta que, a despeito de o pedido de tombamento feito pela Casa da Moeda destacar com bastante ênfase o período em que o edifício abrigou o Museu Nacional (1818-1892), pouco dele se pode identificar na construção atual:

Neste sentido, [...] parece-nos que as razões a priori (sic) apresentadas, embora repletas de conteúdo e comprovação quanto ao que está sendo alegado, terminam por cair no vazio, já que a edificação não exibe qualquer traço desses tempos. Há mais de cem anos,

${ }^{15}$ Em 9 de março de 2018 
o prédio foi completamente remodelado para a instalação do então Arquivo Público Nacional. Assim se mantendo até os dias atuais. Na função de arquivo, o edifício houve ainda que absorver novas intervenções que o modificaram e até mesmo o dilaceraram internamente. (Processo de tombamento 1600-T-10, v. 1, p. 142)

Entende-se, como adverte Siqueira (2016, p. 184) ao analisar processos de tombamento de edifícios no estado de São Paulo, que o passado a que se refere o pedido de tombamento não pode mais ser revelado pelo prédio em questão.

Os pareceres que instruem o processo de tombamento federa ${ }^{16}$ indicam duas soluções, tendo em vista o argumento elaborado pela área técnica do Iphan de que a parte interna do prédio fora bastante descaracterizada pelos usos diversos ao longo de seus dois séculos: (1) ou o tombamento de um edifício isolado, destacando-se que as fachadas seriam o elemento definidor e justificativa para sua preservação; ou (2) o tombamento do edifício como parte de um conjunto, no caso, o do Campo de Santana/Praça da República. ${ }^{17}$

Em consonância com esse parecer técnico da Superintendência do Iphan no Rio de Janeiro, durante a 80ํㅡㄹ reunião do Conselho Consultivo do Patrimônio Cultural e sobre a primeira alternativa, o tombamento do edifício isolado, o arquiteto Nestor Goulart Reis Filho ${ }^{18}$ afirma: "Então as fachadas não devem ser mexidas, nunca, então elas devem ser sempre repostas naqueles termos. A volumetria, também, porque senão é outro edifício". ${ }^{19}$

Observa-se na primeira alternativa a clara referência a um regime de patrimonialização (Davallon, 2015) que depende da construção de vínculos materiais entre o presente e o passado. Segundo Jean Davallon (2015), a patrimonialização de bens de natureza material envolve necessariamente a produção de determinado conhecimento acerca de determinado objeto para que a dimensão comunicacional do patrimônio em relação à sociedade possa se estabelecer (Davallon, 2006). No caso do edifício que abrigou a primeira sede do Museu Nacional, a área técnica do Iphan destaca a materialidade que sobreviveu ao longo desses dois séculos: aquela que nos remete ao prédio como sede do Arquivo Nacional. Os pareceres ressaltam que, do prédio que abrigou o Museu Real, pouco ou nada se conseguiu identificar.

\footnotetext{
${ }^{16}$ Disponível em: http://portal.iphan.gov.br/uploads/atas/ATA_80a_Reuniao_do_Conselho_Consultivo_17_09_2015.pdf.

${ }^{17}$ O Campo de Santana fora tombado pelo Serviço do Patrimônio Histórico e Artístico Nacional em 1938 (processo 99T-38). Sua inscrição foi feita no Livro de Tombo Histórico (fls. 13, inscrição n. 67) e no Livro de Tombo das Belas Artes (fls. 27, inscrição n. 155). Entretanto, em razão das obras para a abertura da Avenida Presidente Vargas, o Campo de Santana teve seu tombamento cancelado por meio de despacho assinado pelo presidente Getúlio Vargas datado de 8 de janeiro de 1943 (Processo P.R. 310/1943).

${ }^{18}$ Conselheiro responsável pela emissão do parecer do CCPC

${ }^{19}$ Ata da 80a Reunião do Conselho Consultivo do Patrimônio Cultural, realizada em 17 de setembro de 2015, na sede do Iphan em Brasilia. Linhas 1119 a 1121, p. 34. Disponível em: http://portal.iphan.gov.br/uploads/atas/ATA_80a_Reuniao_do_Conselho_Consultivo_17_09_2015.pdf. Acesso em: 3 nov. 2017.
} 
Conforme Jean Davallon, a patrimonialização de um bem de natureza material tem envolvido a construção de um vínculo entre presente e passado passível de ser destacado no bem a ser tombado, por meio da produção de saberes geralmente de natureza técnica. A preocupação que pode ser identificada no parecer técnico que instrui o processo nos remete a uma necessidade: o bem deve ser preservado porque a transmissão de seu significado à sociedade depende da manutenção de suas características. Caso não sejam as originais, como é o caso do argumento que se constrói acerca do edifício que abrigou a sede do Museu Nacional, deve-se identificar (grifo nosso) o período mais próximo para que esse saber construído possa legitimar a ação de patrimonialização. No regime de patrimonialização dos bens de natureza material, se houver uma descaraterização severa do bem a ser tombado, não há como garantir a transmissão de sua significação para a sociedade. Jean Davallon (2015) sustenta que esse tem sido o entendimento que tem respaldado uma série de práticas e decisões no campo do patrimônio cultural de natureza material.

A segunda alternativa, o tombamento do prédio integrado ao entorno da Praça da República, é reveladora de outro conjunto de práticas que convive com o tombamento de prédios isolados - os monumentos - desde pelo menos a aprovação da Carta de Veneza, em 1964. Em seu texto, a Carta destaca que "o monumento compreende não só a criação arquitetônica, mas também a moldura em que ela é inserida”, ou seja, seu entorno.

Em todo o processo, e igualmente nas duas soluções apresentadas pelo arquiteto Conselheiro Nestor Goulart, podem-se observar aspectos da trajetória da política de proteção do patrimônio cultural de natureza material por parte do Iphan. Uma tensão que Márcia Sant'Anna identificou ao estudar as práticas de preservação das áreas urbanas empreendidas pelo Iphan entre 1937 e 1990, tensão essa que se originaria em uma determinada compreensão da cidade como monumento e, em outra, da cidade como documento (Sant'Anna, 1995).

A cidade monumento caracterizaria uma determinada compreensão e, consequentemente, uma determinada ação do Iphan que privilegiara edifícios isolados excepcionais por serem (grifo nosso) representativos de determinada arquitetura a partir de critérios de "qualidade arquitetônica, [...] homogeneidade, [...] integridade e autenticidade do conjunto [...]" (Sant'Anna, 1995, p. 135). Seriam, portanto, os edifícios, os monumentos como "expressão arquitetônica fiel de uma determinada época, de um determinado meio, de um determinado programa e de uma determinada técnica" (Costa, Lucio apud Sant'Anna, 1995, p. 136). Retomando a discussão proposta por Jean Davallon (2015) acerca dos regimes de patrimonialização, teríamos, neste caso, claramente, o saber técnico identificando ou não os valores emanados do próprio bem (grifo nosso). Sobre essa prática relacionada ao patrimônio material, Meneses (2010, p. 34) adverte: "continuamos a trabalhar como se o valor cultural fosse identificável exclusivamente a partir de certos traços intrinsecamente presentes nos bens”. 
Já a cidade documento seria aquela representativa de uma compreensão da cidade e de seus processos de preservação, que privilegiaria o "estudo das etapas de formação e desenvolvimento da cidade e a identificação das marcas e dos processos históricos deixados no espaço" (Sant'Anna, 1995, p. 73).

Nas alternativas apresentadas pelo Conselheiro Nestor Goulart, o Conselho do Patrimônio Cultural poderia optar ou por proteger o prédio isolado, como monumento, ou o prédio no seu contexto, ou seja, como documento, o que implicaria uma outra justificativa para o tombamento.

Durante o período de instrução do processo, o engenheiro e historiador da arte Marcus Tadeu Daniel Ribeiro, igualmente técnico do Iphan, defendeu a inscrição do edifício no Livro de Tombo Histórico. ${ }^{20}$ Sua argumentação foi destacada no parecer do Conselheiro Nestor Goulart Reis Filho e na fala do Conselheiro Ulpiano Toledo Bezerra de Meneses, na mesma reunião que aprovou o tombamento do edifício.

Na compreensão de Meneses, no caso específico do prédio objeto do pedido de tombamento, é necessária a distinção entre os valores cognitivos e os valores afetivos.

Para compreendermos melhor suas ponderações, convém fazermos uma pequena digressão. Em conferência proferida no I Fórum do Patrimônio Cultural, realizado em 2010, o Conselheiro Ulpiano Meneses já advertia acerca da necessidade de os agentes do campo do patrimônio cultural, mediante os artigos 215 e 216 da Constituição Federal, aprofundarem a discussão acerca da atribuição de valor aos bens culturais. A compreensão de que os valores não emanam dos bens, mas, sim, lhes são atribuídos tanto pela sociedade quanto pelo corpo técnico dos órgãos de patrimônio é ressaltada pelo conselheiro. ${ }^{21}$ Nessa conferência, ele propõe a classificação dos valores em cinco tipologias, quais sejam: cognitivos, formais, afetivos, pragmáticos e éticos. Poder-se-ia atribuir valor cognitivo quando o bem fosse condição de possibilidade para a construção de conhecimento. Isso implica dizer que o bem não emana conhecimento. Significa transformar o bem em documento porque a ele serão dirigidas determinadas perguntas cujas respostas permitirão conhecermos mais sobre a sociedade por meio do conhecimento daquele bem. Não se trata, portanto, de identificar aspectos de sua construção, ou trajetória, ou ainda a noção de espaço latente no bem; trata-se de dirigir ao bem perguntas e procurar-lhes respostas. Já o valor formal pode ser atribuído quando o que se deseja destacar é a condição de possibilidade de aquele bem ser porta de acesso a um conjunto de experiências estéticas tomadas pelo professor Ulpiano Meneses (2010, p. 36) como "uma mediação que nos faz humanos". O valor afetivo pode ser atribuído a um bem como condição de possibilidade de constituição de vínculos subjetivos de

\footnotetext{
20 Processo Iphan 1600-T-2010, p. 174.

${ }^{21}$ Ver, nas referências ao final do artigo, Meneses (2010).
} 
identidade e pertença. O valor pragmático é atribuído ao bem cujo uso é qualificado e, por isso, qualifica o conjunto de práticas sociais. Por fim, o valor ético é atribuído a um bem como condição de possibilidade de desenvolvimento de um conjunto de práticas que realizem a humanidade, a diversidade e a diferença culturais (Meneses, 2010, p. 37-38).

Voltando à explanação de Ulpiano Meneses na reunião do Conselho Consultivo, acerca do debate que se instaurou a partir do processo, ele destaca que os valores históricos são "uma modalidade de valor cognitivo [...]". ${ }^{22}$ O Conselheiro assinalou que a Constituição de 1988, em seu artigo 216, trouxe uma compreensão diferente daquela do Decreto-Lei 25/1937, a de que também se podem atribuir valores afetivos ao bem cultural, objeto da patrimonialização:

Então, valores afetivos são aqueles, por exemplo, da memória e da identidade (simbólicos). E eles podem estar articulados aos valores que nos permitem conhecer a partir de coisas materiais, como é o caso de uma estrutura arquitetônica. Processos históricos deixam marcas na materialidade mesma da coisa. É bom que saibamos, entretanto, que qualquer exame que se faça do documento, o documento só é documento para o observador e, portanto, só no estado presente é que existe o documento, inclusive o documento de eras prescritas - só existe documento criado pela intenção de conhecimento - e é no estado em que a coisa se encontra que ela tem a sua historicidade possível de ser apreendida. [...] Mas a gente pode entender precisamente a partir dessa contemporaneidade do documento e do observador, a somatória dos processos que levaram àquele estado final. Por exemplo, o meu corpo é historicamente construído a partir do bebê risonho que eu já fui, acreditem. A diferença é radical. Mas é o meu corpo historicamente transformado. Essa perspectiva me parece fundamental. Portanto, é na somatória de vicissitudes que se tem a historicidade toda. E como só se pode tombar aquilo que é empírico, só se pode tombar aquilo que tem um estado atual passível, justamente, de fornecer entendimento sobre sua trajetória histórica. E pela construção histórica procurar entender processos de organização e transformação de sociedades. ${ }^{23}$

Concordando com esta última argumentação, de que os documentos só existem pela intencionalidade de conhecer, o processo de tombamento, da forma como foi instruído, nos revela outra operação patrimonial ainda relacionada à matriz proveniente do Decreto-Lei 25/1937, aquela que, segundo Ulpiano Meneses, se relaciona a uma dimensão declaratória em que é o Estado que declara um bem patrimônio de uma nação.

${ }^{22}$ Ata da 80a Reunião do Conselho Consultivo do Patrimônio Cultural realizada em 17 de setembro de 2015, na sede do Iphan, em Brasília. Linha 1147, p. 35. Acesso em 3 nov. 2017.

${ }^{23}$ Idem. Linhas 1157 a 1175, p. 34-35 
Em 2012, a Revista do Patrimônio Cultural do Rio de Janeiro publicou, no número do segundo semestre, reportagem sobre pesquisa arqueológica no primeiro pavimento do prédio objeto de tombamento, feita por Guadalupe do Nascimento Campos, coordenadora do Projeto Arqueológico do Antigo Museu Real, com "apoio institucional do Instituto de Arqueologia Brasileira - IAB, além de acompanhamento de pesquisadores da Gerência de Arqueologia da (sic) Instituto Rio Patrimônio da Humanidade e do Iphan" (Campos, 2012, p. 52). A referida pesquisa arqueológica foi realizada em 2010. Conforme Ulpiano Bezerra de Meneses asseverou, "processos históricos deixam marcas na materialidade mesma da coisa". A depender da pergunta feita a essas camadas instituídas arqueológicas, elas podem nos informar acerca de estruturas primevas do próprio edifício, mas também estruturas e objetos que se acredita sejam anteriores à sua própria construção (Campos, 2012, p. 53). Além de cachimbos, búzios, cacos de porcelana, foram encontrados 63 chifres bovinos, que podem ter relação com o fato de o local - Campo de Santana - ter abrigado uma Praça de touros (ibidem). O artigo nos informa que foram encontrados baldrames de pedra de cor amarelada que provavelmente são relacionados ao período de construção do edifício a mando do comerciante português João Rodrigues Pereira de Almeida. Tanto a arqueóloga Guadalupe Campos quanto o historiador Marcus Tadeu Daniel Ribeiro ${ }^{24}$ acreditam que, quando o prédio foi vendido para a Coroa Portuguesa, para ali instalar o Museu Real, este ainda se encontrava em construção.

Acreditamos que o fato de um dos maiores comerciantes portugueses da cidade, João Rodrigues Pereira de Almeida, ${ }^{25}$ ter comprado terreno para construção de sua residência (posteriormente sede do Museu Real) possa ser indicativo dos efetivos melhoramentos promovidos na região que compreendia os limites da rua da Vala (Uruguaiana, atualmente) e o Mangal de São Diogo (atual região da Praça Onze/Cidade Nova). Os documentos arrolados no processo de tombamento podem informar que essa região, como o próprio nome nos permite inferir, era uma região de mangue, com vegetação rasteira, sujeita a inundações, também conhecida como Campo da Cidade: "Tratava-se de uma região situada após a rua da Vala (atual Uruguaiana). Inicialmente conhecido como Campo da Cidade, por vezes sujeito a alagamentos. Foi sendo aterrado à medida que a cidade se expandia para oeste. Formava-se assim um amplo campo também chamado de Areal" (Segantini, 2015, p. 102).

Pelas condições geográficas, nos séculos XVII e XVIII era um local desvalorizado e distante. O engenheiro e jornalista Vivaldo Coracy sinaliza que, no Setecentos, a cidade do Rio de Janeiro, por seu crescimento, havia transposto a rua da Vala, e se estabeleceram

\footnotetext{
${ }^{24}$ Processo Iphan 1600-T-2010, p. 174.

25 João Rodrigues Pereira de Almeida era um comerciante de grosso trato. Assim se designavam aqueles que eram grandes atacadistas inscritos na Junta do Comércio. Com a chegada da Corte Portuguesa ao Rio de Janeiro, em 1808, esses comerciantes se beneficiaram ainda mais, uma vez que, ao financiarem obras e melhoramentos, recebiam cargos e títulos fornecidos pelo governo português na América.
} 
chácaras naquele local, como a de Mendes de Almeida, Gonçalo Nunes e do cônego Antônio Pereira da Cunha. Posteriormente, na chácara do cônego Pereira da Cunha, foi construída a Igreja de Santana, mandada erguer por uma irmandade de mulatos devotos e que ficou pronta em 1735 (Coracy, 1965, p. 159-160), passando a nomear o local. Outra irmandade de negros, a Irmandade de São Domingos, igualmente construiu seu templo anteriormente, em 1710. As referências nos indicam que a igreja de Santana situava-se onde hoje é o prédio da Central do Brasil.

Outro exemplo da desvalorização do local ao longo do século XVIII é que para lá foram encaminhados os ciganos deportados no Reinado de D. João V (1706-1750), que se instalaram entre a Praça do Rossio Grande (Praça Tiradentes atual) e o Campo de Santana. O governador do Rio de Janeiro, Antônio Gomes Freire de Andrade, $1^{\circ}$ Conde de Bobadela (1733-1763), aplicou a referida legislação portuguesa, ${ }^{26}$ que obrigava os ciganos a se concentrarem na região para além da rua da Vala (atual Uruguaiana), onde hoje é a Praça Tiradentes (Cavalcanti, 2004, p. 147). Dessa ocupação adveio o nome da rua dos Ciganos, que era a via que ligava o então Campo dos Ciganos ao Campo de Santana. O imóvel construído por João Rodrigues Pereira de Almeida no início do Oitocentos e que viria a sediar o Museu Real situava-se na esquina mesma onde a rua dos Ciganos terminava.

Segundo a bibliografia consultada, foi no final do Setecentos que o vice-rei D. José Luís de Castro, $2^{\circ}$ Conde de Resende, ordenou as obras de drenagem e aterramento do Campo, o que pode indicar necessidade de expansão da cidade. Pode-se inferir que essas obras permitiram que, no início do século XIX, ali fossem construídos palacetes que acabaram por abrigar uma elite que se consolidava no Rio de Janeiro, alterando uma determinada geografia política da cidade.

Anacleto Elias da Fonseca, por exemplo, negociante no Rio de Janeiro desde pelo menos 1753 (Fragoso, 2001, p. 118), foi um daqueles que mandou construir palacete no local que, poucos anos depois, sediou a residência de Marcos de Noronha e Brito, Conde dos Arcos, último vice-rei do Brasil. Ao perder o cargo com a chegada da Corte ao Brasil, o Conde dos Arcos foi nomeado Ministro da Marinha e do Ultramar, permanecendo no Rio de Janeiro. Em 1822, o Conde dos Arcos retornou a Portugal, deixando vazio o palacete, que foi vendido ao governo de Pedro I e passou a sediar o Senado do Império (1825-1926). Outro palacete era de Francisco José da Rocha, Conde de Itamarati, cuja residência era o Palácio do Itamarati, na rua Larga.

Acreditamos que se possa inferir que a chegada da Corte Portuguesa ao Brasil em 1808 contribuiu para essa alteração geopolítica urbana, que amplia os espaços de poder da cidade

${ }^{26}$ Em 20 de setembro de 1760, D. José I, rei de Portugal, estabeleceu a Lei sobre os ciganos, para o Brasil (CAVALCANTI, 2004). 
para além do Terreiro do Paço, alcançando o Campo de Santana e chegando à Quinta da Boa Vista, em São Cristóvão. Acerca do adensamento simbólico do Campo de Santana, Segantini reitera citando matéria do jornal O Chronista, de 1838:

Lembre-se a câmara que é nesse mesmo campo que está situado o Museu Nacional, o paço do senado, o quartel general, a casa de suas próprias sessões, onde também se reúne o jury; lembre-se a câmara que é por ali que passa o monarca quando vem da quinta da Boa Vista para o palácio da cidade, e que por todos os motivos é esse um dos lugares mais frequentados da cidade, não só por nacionais como por estrangeiros, e alguma coisa se deve fazer para não parecermos estar na última linha das nações civilizadas. Faça a câmara que, querendo evitar as madeiras e cantaria que estão na frente da casa do snr. H. J. De A., não vamos cair nas imundícias com que se está aterrando o campo. - Que belo aterro! É o mais próprio para a salubridade pública. (O Chronista, n. 256,17 nov. 1838 , p. 4)

Além das instituições citadas em O Chronista, esse lugar abrigou, ao longo do século XIX, o Corpo de Bombeiros, o Paço da Cidade do Rio de Janeiro - Paço Municipal, ${ }^{27}$ a Estação de Trem D. Pedro II, o Teatro Lírico Fluminense, a Academia Imperial de Medicina, a residência do Intendente-geral da Polícia do Rio de Janeiro, a Escola Normal e a Escola Rivadavia Correa.

Além dessas residências e edifícios públicos, o Campo de Santana também recebeu uma série de festas e comemorações.

Em 1810, o Campo de Santana foi sede dos festejos em homenagem ao casamento da filha mais velha de D. João VI e da rainha Carlota Joaquina, D. Maria Teresa de Bragança. Anos mais tarde, o mesmo Campo de Santana sediou o segundo dia de festejos em decorrência da cerimônia de Aclamação de D. João VI, em 6 de fevereiro de 1818. Sobre essa cerimônia, Jaqueline Hermann nos informa que a aclamação ${ }^{28}$ teve início no Terreiro do Paço, ${ }^{29}$ mas se entendeu pelo

Campo de Santana, outro polo importante. Um palacete de madeira foi erguido para abrigar Sua Majestade e a família real e transformou-se no centro do segundo dia dos festejos reservado às manifestações populares. Os soldados dos batalhões fizeram evoluções, seguidos dos dançarinos do Real Teatro, além da corrida de touros. No dia 8 a

\footnotetext{
${ }^{27}$ Derrubado na década de 1940 para a abertura da Avenida Presidente Vargas.

${ }^{28}$ No caso de Portugal, as cerimônias de coroação foram substituídas pelas de aclamação, associadas ao mito sebastianista. Ao desaparecer no norte da África, D. Sebastião teria levado consigo a Coroa do Reino de Portugal, inviabilizando as cerimônias de Coroação naquele Reino.

29 Sobre a Cerimônia de Aclamação de D. João VI em 6 de fevereiro de 1818, no Paço Imperial, ver Castro, 2014
} 
real família e o soberano voltaram ao Palacete, de onde assistiram a uma queima de fogos, cujo ponto culminante foi a expressão "Viva El Rei" iluminada no céu, quando D. João Recebeu para a cerimônia do beija mão.

Para além do templo, arcos, palacetes e fogos, a iluminação foi um capítulo à parte. No Campo de Santana, Oliveira Lima cita 102 pirâmides luminosas com brilho e gosto suficientes para "fazer pensar nas Tulheiras e nos Campos Elísios iluminados". Houve verdadeira disputa entre corporações, repartições e particulares na elaboração da iluminação e uma só casa teria se enfeitado com 6.000 lampiões. (Hermann, 2007, p. 146)

Não foi outro o espaço escolhido para os festejos relacionados ao casamento de D. Pedro com a Princesa Leopoldina, ocorrido em outubro de 1818 . $^{30}$ É entre essas duas cerimônias, a aclamação de D. João VI e os festejos comemorativos do casamento de D. Pedro e Dona Leopoldina, que é criado o Museu Real, em junho de 1818.

Anos mais tarde, em 12 de outubro de 1822, o Campo de Santana acolheu a cerimônia de Aclamação de D. Pedro.

Figura 1 - Aclamação de D. Pedro I, imperador do Brasil

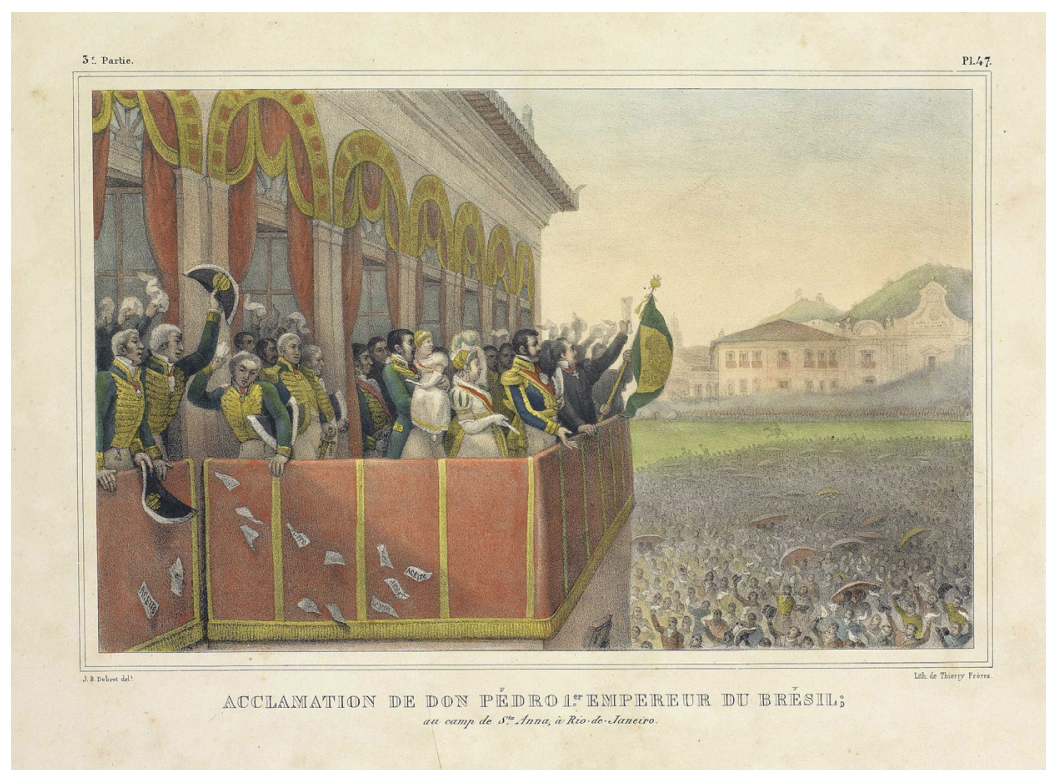

Fonte: http://objdigital.bn.br/acervo_digital/div_iconografia/icon393054/icon393054_180.jpg

30 O casamento propriamente dito foi realizado em Viena, em 13 de maio de 1817. D. Pedro foi representado pelo tio de Leopoldina. Sua chegada ao Brasil ocorreu em novembro de 1817. 
Segundo Vivaldo Coracy (1965, p. 169), é com a Independência do Brasil que o Senado do Império aprova a substituição oficial do Campo de Santana por Campo da Aclamação. Já no livro Rio de Janeiro Imperial, de Adolfo Morales de Los Rios, há mais detalhes:

Praça de Aclamação - Antigo Campo de Santana; assim chamado em virtude da igreja dessa invocação, que estava situada no lugar ora ocupado pela Estação Central da Estrada de Ferro. Em obediência à portaria do ministério do Império de 22 de outubro de 1822, segundo determinação do Imperador D. Pedro I, passou a chamar-se Praça da Aclamação. A denominação relembraria, assim, aos pósteros não só a data de 7 de setembro como também perpetuaria "por um modo público a lembrança do lugar em que recebeu D. Pedro dos seus fiéis súditos tão agradáveis provas de respeito e afeição". Em virtude dos fatos decorrentes da abdicação de D. Pedro, o povo passou a denominá-lo, depois de 7 de abril de 1831, de campo da Honra. Na mesma ocasião lhe foram dadas outras denominações, como Campo da Regeneração e Campo da Liberdade. Mas as denominações de Campo ou Praça da Aclamação foram as mantidas até a Proclamação da República. (Los Rios, s. d., p. 198)

Observa-se que o mesmo campo que sediou a aclamação do imperador Pedro I sediou, igualmente, as manifestações por sua abdicação, em 7 de abril de 1831, e também a própria proclamação da República, em 1889.

O pedido de tombamento federal feito pela Casa da Moeda reitera a importância do prédio por ter abrigado o primeiro museu do país. Não que as instituições que se sucederam naquele espaço tenham menor importância, mas, sem dúvida, o Museu Nacional se projeta nacional e internacionalmente, àquela época e ao longo de todo o século XX.

O parecer 008/2010, que se apresenta na sequência do processo elaborado pelo engenheiro e historiador da arte Marcus Tadeu Daniel Ribeiro, aponta para a possibilidade de tombamento no Livro de Tombo Histórico. O parecer 008/2010 se alinha ao parecer anterior 005/2010 - ao destacar que as alterações promovidas pela necessidade de instalação do Arquivo Nacional em 1905

Alteraram substancialmente os partidos e o programa arquitetônico do prédio, interferindo na concepção do imóvel de maneira incompatível com o classicismo de que se reveste o vocabulário arquitetônico do prédio. Sua entrada ficou congestionada de colunas de ferro, eliminando-se os espaços amplos e despojados que caracterizam a arquitetura neoclássica.

A construção do imóvel em sua compleição original, aquela inaugurada em 1819, obedeceu ao vocabulário classicista que marcou a transição da arte da fase colonial para o século XIX. (Processo de Tombamento 1600-T-2010, p. 187-188) 
Diferentemente do parecer 005/2010, Ribeiro não recomenda a inscrição no Livro de Tombo das Belas Artes, mesmo que restrito às suas fachadas. Defende seu tombamento no Livro de Tombo Histórico, que foi a decisão tomada pelo Conselho Consultivo.

Destaque-se que o fato de haver, naquele contexto de 2010, um projeto arquitetônico de restauração e requalificação do prédio foi elemento considerado no sentido de que a restauração, aliada ao tombamento federal, poderia devolver à população um espaço de cultura.

Em relação ao processo de tombamento, uma última observação se faz necessária. Quem acessa o processo de tombamento físico, mas também sua versão em meio digital, depara com o seguinte título na capa do volume le dos anexos le 2: "Prédio à Rua Praça da República, 26 (antiga sede do Arquivo Nacional) no Município do Rio de Janeiro, Estado do Rio de Janeiro". No momento de atribuição de título ao processo, nos parece que a versão do prédio como sede do Arquivo Nacional é a que foi destacada. Dentre tantas instituições que tiveram ali seu endereço, foi a de sede do Arquivo Nacional que acabou consolidada pelo título do processo.

\section{Considerações finais}

No que se refere às políticas de patrimônio e aos usos do passado, as questões que podem ser analisadas por meio do processo de tombamento em análise nos sinalizam que as "fontes" apresentadas são tomadas como o passado em si, consequentemente como prova da existência deste, sem um debate acerca dessa seleção, ou do lugar de fala de quem construiu seus argumentos. No caso da avaliação da viabilidade do tombamento do prédio, a área técnica optou por trabalhar a partir de documentação apresentada pelo proponente, levando em conta relatórios que se utilizaram dos livros de viajantes e que, preferencialmente, contivessem imagens, especialmente porque se tratava de cotejar a aparência do imóvel em relação ao seu estado em 2009/2010. Nesse sentido, esses livros se transformaram em prova do que a materialidade da arquitetura, por sua vez, deixava ver e revelar. Sob a alegação de que não havia mais no prédio sinais materiais do museu que existiu ali, o processo de tombamento assumiu, na designação do bem a ser tombado, que se tratava de "Prédio à rua Praça da República, 26 (Antiga sede do Arquivo Nacional), no Município do Rio de Janeiro, Estado do Rio de Janeiro", dificultando, a nosso ver, a possibilidade de que ele possa ser lembrado como primeira sede do Museu Nacional, isso inclusive em termos de recuperação da informação. Durante a 80ª reunião do CCPC, o diretor do Departamento de Patrimônio Material, Prof. Dr. Andrey Schlee, lembrou que as cartas internacionais e o Iphan recomendam que, nos prédios históricos tombados e abertos ao público, se tenha pelo menos uma sala onde se apresente a trajetória do edifício em destaque, de forma que "as diversas camadas presentes na edificação, 
e todo o simbolismo inerente a ela possa ser lido pela população [...]". Observa-se assim que essa produção de enunciados que transforma um edifício em patrimônio agencia uma gama de conteúdos e saberes que, no limite, exercem uma fala de autoridade. Não é suficiente, portanto, que o edifício seja elevado à categoria de monumento histórico; é necessário que tanto sua materialidade quanto sua carga simbólica sejam compartilhadas no presente como um documento/monumento, porque a sua transformação em documento histórico se dá por sua capacidade de responder às demandas do presente.

\section{Referências}

ANDRADE, Rodrigo Melo Franco de. Rodrigo e o Sphan: coletânea de textos sobre o patrimônio cultural. Rio de Janeiro: MinC/Fundação Nacional Pró-Memória, 1987.

BARTHES, Roland. O rumor da língua. São Paulo: Martins Fontes, 2004.

CAMPOS, Guadalupe do Nascimento. Arqueologia no antigo Museu Real - Praça da República. Rio Patrimônio Cultural, Revista do Patrimônio Cultural da Cidade do Rio de Janeiro, Rio de Janeiro, ano 2 , n. 2, p. 52-53, 2012. Disponível em: http://www.rio. rj.gov.br/dlstatic/10112/6442824/4172717/revista2. compressed.pdf. Acesso em: maio 2018.

CASTRO, Giovanna. Servir e celebrar orei: o cerimonial de aclamação de D. João VI e a Casa Real Portuguesa no Rio de Janeiro. In: ENCONTRO ESTADUAL DE HISTÓRIA DA ANPUH-SP, XXII., 2014, Santos. Anais... Disponível em: http://www.encontro2014. sp.anpuh.org/resources/anais/29/1406685128 ARQUIVO_ApresentacaoSTGiovannaMilanezde Castro.pdf. Acesso em: jul. 2018.

CAVAlCANTE, Ivana Medeiros Pacheco. Arquiteturas temporais: a prática historiográfica do patrimônio cultural. 2016. Dissertação (Mestrado em História) - Universidade de Brasília. Brasília, 2016.

CAVALCANTI, Nireu Oliveira. Crônicas históricas do Rio colonial. Rio de Janeiro: Civilização Brasileira, 2004.

CORACY, Vivaldo. Memórias da cidade do Rio de Janeiro. Rio de Janeiro: J. Olympio Ed., 1965.
DANTAS, Regina Maria Macedo Costa. A casa do imperador: do Paço de São Cristóvão ao Museu Nacional. 2007. Dissertação (Mestrado em Memória Social) - Universidade Federal do Estado do Rio de Janeiro. Rio de Janeiro, 2007.

DAVALLON, Jean. Le Don du Patrimoine: une approche comunicationnelle de la patrimonialisation. Paris: Lavoisier, 2006.

DAVALLON, Jean. Memória e patrimônio. Por uma abordagem dos regimes de patrimonialização. In: TARDY, Cécile; DODEBEI, Vera (org.). Memória e novos patrimônios. Marseille: Open Edition Press, 2015.

FRAGOSO, João Luís. O antigo regime nos trópicos: a dinâmica imperial portuguesa (séculos XVI-XVIII). Rio de Janeiro: Civilização Brasileira, 2001.

FRAGOSO, João Luís. Homens de grossa aventura: acumulação e hierarquia na Praça Mercantil do Rio de Janeiro (1790-1830). Rio de Janeiro: Civilização Brasileira, 1998.

GONÇALVES, Aureliano Restier. Cidade de São Sebastião do Rio de Janeiro: terras e fatos. Rio de Janeiro: Secretaria Municipal das Culturas/Arquivo Geral da Cidade do Rio de Janeiro, 2004.

GONÇALVES, José Reginaldo Santos. A retórica da perda: discursos sobre o patrimônio cultural no Brasil. Rio de Janeiro: Ed. UFRJ, 1996.

HERMANN, Jacqueline. O rei da América. Notas sobre a aclamação tardia de D. João VI no Brasil. Topoi, v. 8, n. 15, 2007. Disponível em: http://www.scielo.br/ 
pdf/topoi/v8nl5/2237-101X-topoi-8-15-00124.pdf. Acesso em: jul. 2018.

LOPES, Maria Margaret. O Brasil descobre a pesquisa científica: os museus e as ciências naturais no século XIX. São Paulo: Hucitec; Brasília: Ed. UnB, 2009.

LOPES, Maria Margaret. Minerales y fósiles para escudriñar el país, abarrotar las vitrinas y educar a la gente. In: ACHIM, Miruna; PODGORNY, Irina (org.). Museos al detalle: colecciones, antigüedades e historia natural, 1790-1870. Rosario: Prohistoria Ediciones, 2013. p. 179-200.

LOPES, Maria Margaret; FIGUEIROA, Silvia F. de Mendonça. Le CNAM inspire une idée de musée aux tropiques: la collection des machines et des modèles industrielles de la Sociedade Auxiliadora da Indústria Nacional - SAIN (Brésil, 1827-1878). Cahiers d'histoire du CNAM. (no prelo, 2019).

LOS RIOS, Adolfo Morales de. O Rio de Janeiro imperial. Rio de Janeiro: A Noite, s. d.

MENESES, Ulpiano Toledo Bezerra de. O campo do patrimônio cultural: uma revisão de premissas. In: FÓRUM DO PATRIMÔNIO CULTURAL, 1., 2010, Ouro Preto. Anais... Ouro Preto, 2009. Disponível em: http://portal.iphan.gov.br/uploads/ckfinder/ arquivos/MENESES_Ulpiano_O-campo-dopatrimonio-cultural---uma-revisao-de-premissas. pdf. Acesso em: out. 2018.
O CHRONISTA. Rio de Janeiro, 17 nov. 1838. Disponível em: http://memoria.bn.br/DocReader/ Hotpage/HotpageBN.aspx?bib=702811\&pagfis= 912\&url=http://memoria.bn.br/docreader\#. Acesso em: maio 2018.

REZENDE, Maria Beatriz; GRIECO, Bettina; TEIXEIRA, Luciano; THOMPSON, Analucia. Serviço do Patrimônio Histórico e Artístico Nacional - Sphan. In: REZENDE, Maria Beatriz; GRIECO, Bettina; TEIXEIRA, Luciano; THOMPSON, Analucia. (org.). Dicionário Iphan de patrimônio cultural. Brasília: Iphan/DAF/Copedoc, 2015.

SANT'ANNA, Marcia Genésia de. Da cidademonumento à cidade-documento. 1995. Dissertação (Mestrado em Arquitetura) - Universidade Federal da Bahia. Salvador, 1995.

SEGANTINI, Verona Campos. Maneira decente e digna de expor aos olhos do público: modos de exibição da História Natural. 2015. Tese (Doutorado em Educação) - Universidade Federal de Minas Gerais. Belo Horizonte, 2015.

SIQUEIRA, Lucília Santos. O conhecimento sobre o passado dos bens tombados que abrigam museus: o solar do Barão de Jundiaí (Jundiaí/SP) e a casa de Prudente de Morais (Piracicaba/SP). Estudos Históricos, Rio de Janeiro, v. 29, n. 57, 2016. 